\title{
ANÁLISE DE ÍNDICES MORFOMÉTRICOS NO BAIXO CURSO DA BACIA HIDROGRÁFICA DO RIO JEQUITINHONHA (BA)
}

\author{
Giovani Bino Rodrigues ${ }^{(a)}$, Archimedes Perez Filho ${ }^{(b)}$ \\ (a) Mestrando do Programa de Pós-Graduação em Geografia da Universidade Estadual de Campinas (UNICAMP) \\ E-mail: giovanibino@ige.unicamp.br \\ (b) Professor Titular do Programa de Pós-Graduação em Geografia da Universidade Estadual de Campinas \\ (UNICAMP). E-mail: archi@ige.unicamp.br
}

\section{EIXO: SISTEMAS GEOMORFOLÓGICOS: ESTRUTURA, DINÂMICA E PROCESSOS}

\section{Resumo}

O perfil longitudinal e o fator de simetria topográfica transversa são importantes ferramentas para o estudo da rede de drenagem. Esse artigo aplica tais índíces morfométricos para analisar o baixo curso do rio Jequitinhonha, localizado no sul do Estado da Bahia. Foram associados dados pedológicos, geomorfológicos, geológicos e litológicos com perfil longitudinal para mostrar as características do canal fluvial. Os resultados foram confrontados com imagens orbitais da constelação Digital Globe e apontaram evidências sobre a dinâmica pretérita e atual do canal fluvial.

Palavras-chave: Morfometria, Perfil Longitudinal, Fator de Simetria Topográfica Transversa,

\section{Introdução}

O rio Jequitinhonha nasce no município de Serro, em Minas Gerais, e percorre todo este Estado e o da Bahia até seu delta no município de Belmonte (BA). O baixo curso está majoritariamente situado no compartimento inferido por Ab`Sáber (2003) como mares de morros, ou seja, área mamelonares tropicalatlânticas florestadas. A bacia tem área total de aproximadamente $70.315 \mathrm{~km}^{2}$, e o baixo curso do rio Jequitinhonha abrange aproximadamente $3.996 \mathrm{~km}^{2}$ (IBGE, 2005). Este artigo tem como objetivo analisar dois parâmetros morfométricos no baixo curso dessa bacia hidrográfica (Figura 1).

A área de estudo contém três unidades geomorfológicas. A porção mais próxima da costa em contato com o oceano Atlântico é composta por planícies costeiras quaternárias, com influências fluviais e marinhas, contendo aluviões e terraços fluviais, fluviomarinhos e marinhos, e sujeita a inundações. Em contato com tais planícies e terraços e localizada na parte central, há a bacia sedimentar do Terciário associada ao grupo Barreiras com relevos de topos tabulares, capeados por sedimentos que recobrem rochas cratonizadas do Escudo Oriental lateritizados em superfície e entalhados por drenagem dendrítica ou paralelo-ramificada. A porção mais distante das planícies costeiras tem embasamento cristalino préCambriano e é caracterizada por relevos de topos planos, encostas predominantemente convexas e 


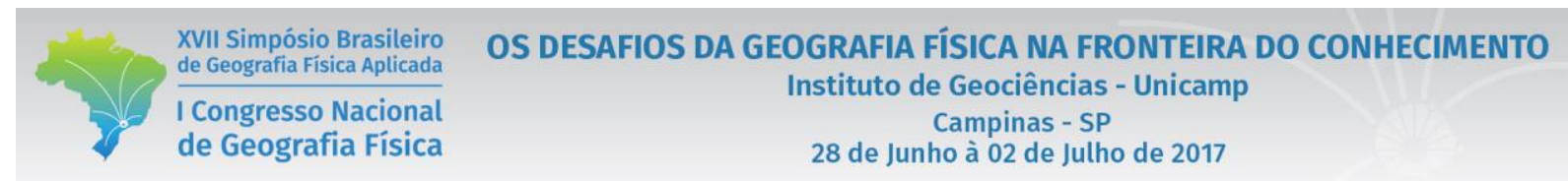

convexa-côncavas, serras e maciços montanhosos, refletindo os alinhamentos estruturais das rochas intensamente metamorfizadas e cortadas por gargantas do tipo apalacheano (CBPM, 2000 e SEI, 2004). O primeiro índice utilizado foi o perfil longitudinal que evidencia a declividade do canal fluvial da nascente até a foz, relacionando-a com a altimetria do percurso (Christofoletti, 1980), e auxilia a caracterização de possíveis influências estruturais, litológicas e climáticas que deformam a rede de drenagem. O segundo índice foi o Fator de Simetria Topográfica Transversa (FSTT) (Cox, 1994), que permite descobrir a existência de um deslocamento do rio em relação ao eixo médio da bacia hidrográfica.

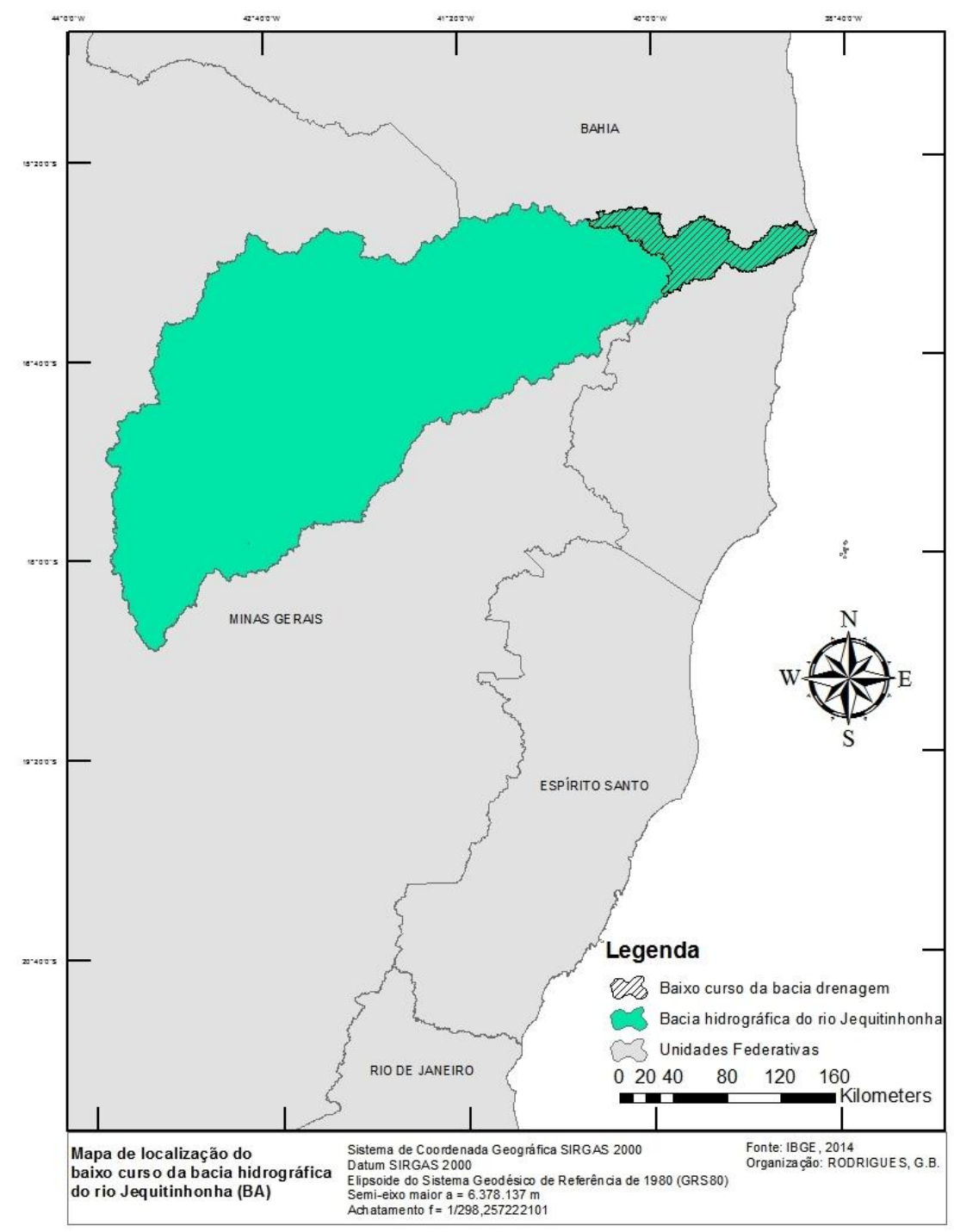

Figura 1 - Mapa de localização do baixo curso da bacia hidrográfica do rio Jequitinhonha (BA) 


\section{Metodologia}

O mapa de localização da área de estudo, com destaque no rio Jequitinhonha, foi vetorizado por meio de um mosaico de imagens Worldview-02 na escala de trabalho 1:250000, com imagens entre 2015 e 2016, e foi utilizada a base de unidades federativas do IBGE de 2014. As curvas de nível também são da base do IBGE com equidistância de 100 metros, porém foram ajustadas de acordo com as curvas geradas pelo MDE (Modelo Digital de Elevação) SRTM, com resolução espacial de 30 metros, interpolado para correção de pixels zero e ruídos no ArcGis 10.5.

O perfil longitudinal foi gerado por meio da mensuração do comprimento do canal e das marcações nas interseç̧ões com as linhas altimétricas em intervalos de 20 metros. A linha de tendência, também chamada de linha de melhor ajuste, foi feita no Microsoft Excel 2010 para evidenciar as áreas de erosão e deposição sedimentar ao longo do rio, assim como para indicar possíveis efeitos de deformação. Diversos autores, como Tanner (1971) e Hack (1973), expõem equações que expressam representações de ajustes, porém nota-se que elas variam de acordo com as características altimétricas do local. Portanto, a escolha da melhor linha de tendência foi baseada no comportamento dos pontos e no coeficiente de determinação $\left(\mathrm{R}^{2}\right)$ mais próximo a 1, assegurando a confiabilidade da linha.

Os dados pedológicos, geomorfológicos, geológicos e litológicos são da base disponibilizada pela Superintendência de Estudos Econômicos e Sociais da Bahia (SEI, 2004) com escala 1:500000, exceto o mapa pedológico, que apresenta escala 1:650000.

O FSTT foi gerado a partir da média dos vetores da rede de drenagem, como proposto por Cox (1994). O cálculo desse fator é feito pela equação $\mathrm{T}=\mathrm{Da} / \mathrm{Dd}$, sendo que $\mathrm{T}$ é o fator simétrico, $\mathrm{Da}$ é a distância da linha média do eixo da bacia de drenagem até a linha média do cinturão do canal ativo e Dd é a distância da linha média da bacia até o divisor da bacia d. Nessa equação, a drenagem com maior simetria tem valores próximos a $\mathrm{T}=0$.

Os paralelos Da e Dd foram realizados com equidistância de 2 quilômetros e mostraram-se mais eficazes ns análises do que os usados por Cox (1994), que têm 4 quilômetros. No trecho meândrico, onde ocorreram duas ou mais intersecções com o canal fluvial - P46, P48, P49, P53 -, a distância da linha média do eixo da bacia de drenagem foi calculada até a metade da distância entre as intersecções (Figura $3)$. 


\section{Resultados e discussões}

O gráfico de perfil longitudinal foi associado com dados pedológicos, geomorfológicos, geológicos e litológicos (Figura 2). Essas informações foram acrescidas para mostrar as características físicas do percurso do canal fluvial. É importante deixar claro que tais informações referem-se estritamente ao trajeto do rio, e não de toda a área do baixo curso do rio Jequitinhonha (BA). A curva do perfil longitudinal e a linha de tendência, que está ligeiramente acima da linha do perfil, mostraram um trecho de erosão até aproximadamente o quilômetro 70 do curso do canal fluvial, e o trecho seguinte, que vai até a foz do rio, apresentou um afastamento negativo do perfil, ou seja, valores menores que a linha de melhor ajuste, demonstrando a deposição sedimentar.

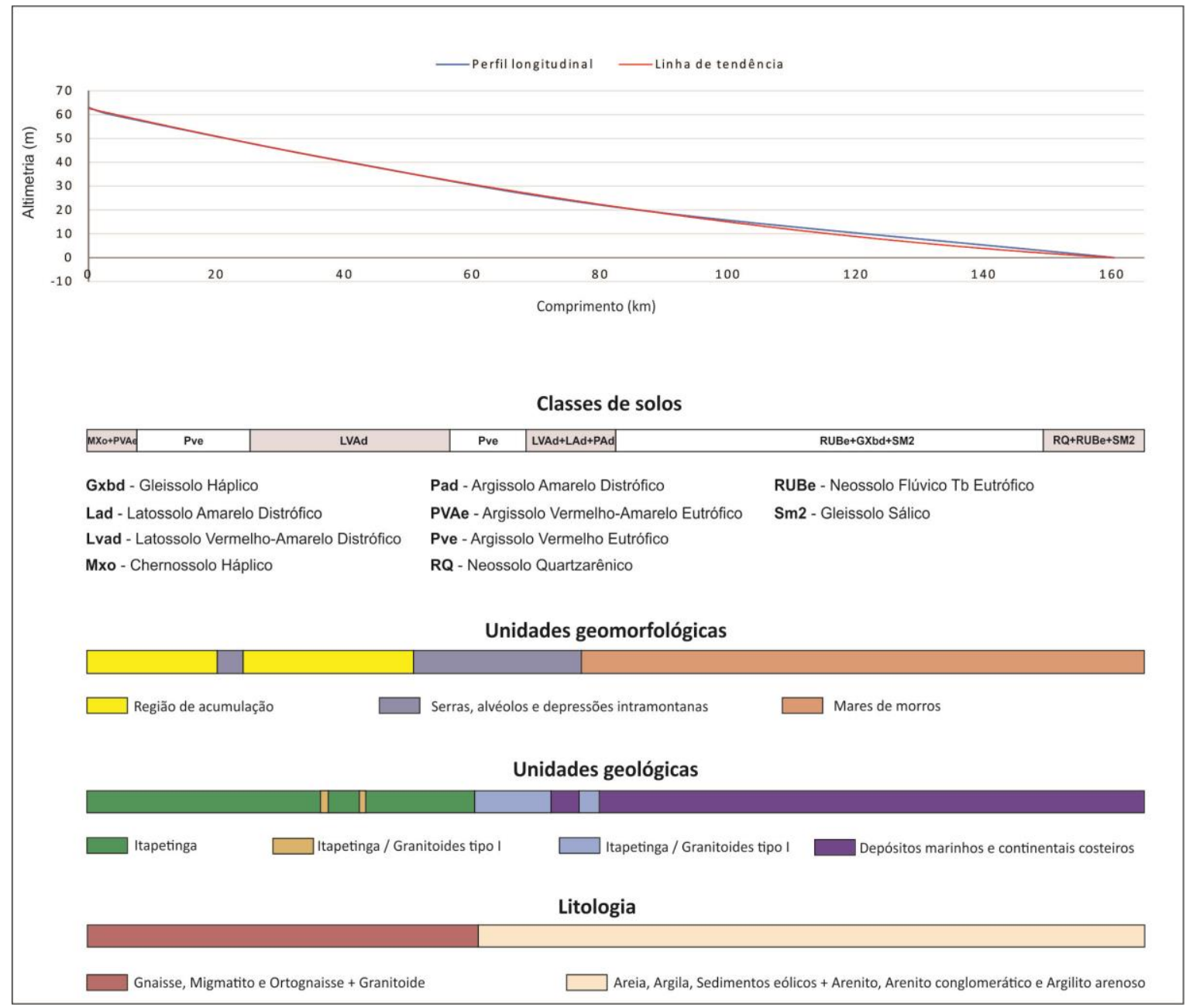

Figura 2 - Perfil longitudinal do baixo curso do rio Jequitinhonha (BA). Fonte: CBPM,2000 e SEI,2004. Organização: RODRIGUES, G.B. 


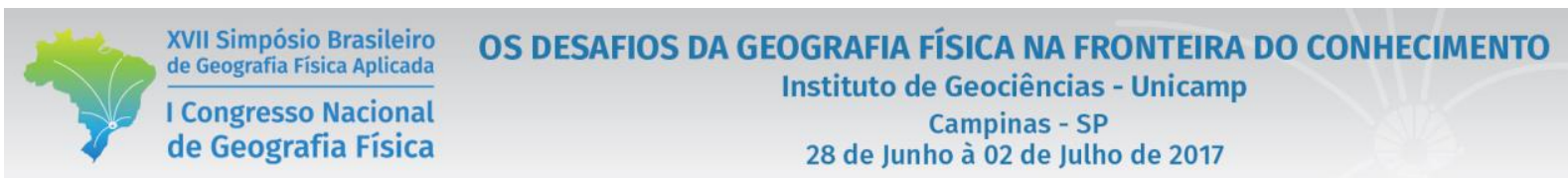

O FSTT delimitou o trajeto que o rio pode ou não ter percorrido no passado e o deslocamento atual, com os maiores valores entre P49 e P55 - maior valor P50, apresentando T=0,95, e menor valor, mais simétrico, em P27 com T= 0,00072.

Tabela I - Cálculo do Fator de Simetria Topográfica Transversa (FSTT)

\begin{tabular}{|llll} 
& Da $(\mathbf{m})$ & Dd $(\mathbf{m})$ & T \\
\hline P1 & 5679 & 27880 & 0,203694 \\
P2 & 5749 & 27031 & 0,212682 \\
P3 & 8119 & 23917 & 0,339466 \\
P4 & 8633 & 22255 & 0,387913 \\
P5 & 7366 & 20272 & 0,363358 \\
\hline P6 & 8760 & 20907 & 0,418998 \\
\hline P7 & 9068 & 19526 & 0,464406 \\
\hline P8 & 8134 & 20112 & 0,404435 \\
\hline P9 & 6509 & 23164 & 0,280996 \\
\hline P10 & 3668 & 20753 & 0,176746 \\
\hline P11 & 3138 & 21388 & 0,146718 \\
\hline P12 & 2795 & 21904 & 0,127602 \\
\hline P13 & 1835 & 21879 & 0,08387 \\
\hline P14 & 1863 & 21545 & 0,08647 \\
\hline P15 & 1042 & 21828 & 0,047737 \\
\hline P16 & 71 & 23017 & 0,003085 \\
\hline P17 & 195 & 23289 & 0,008373 \\
\hline P18 & 856 & 22163 & 0,038623 \\
\hline P19 & 448 & 22295 & 0,020094 \\
\hline P20 & 748 & 21667 & 0,034523 \\
\hline P21 & 454 & 21195 & 0,02142 \\
\hline P22 & 1573 & 17864 & 0,088054 \\
\hline P23 & 233 & 15704 & 0,014837 \\
\hline P24 & 245 & 14432 & 0,016976 \\
\hline P25 & 2381 & 13470 & 0,176763 \\
\hline P26 & 2799 & 12598 & 0,222178 \\
\hline P27 & 6 & 8338 & 0,00072 \\
\hline P28 & 1288 & 10069 & 0,127917 \\
P29 & 503 & 8759 & 0,057427 \\
\hline P30 & 1068 & 8520 & 0,125352 \\
\hline & & & \\
\hline
\end{tabular}

\begin{tabular}{|llll|}
\hline & Da $(\mathbf{m})$ & Dd $(\mathbf{m})$ & T \\
\hline P31 & 1118 & 8950 & 0,124916 \\
\hline P32 & 2199 & 8289 & 0,265291 \\
\hline P33 & 2665 & 8278 & 0,321938 \\
\hline P34 & 915 & 8284 & 0,110454 \\
\hline P35 & 458 & 8581 & 0,053374 \\
\hline P36 & 2255 & 9572 & 0,235583 \\
\hline P37 & 4224 & 11000 & 0,384 \\
\hline P38 & 4587 & 9669 & 0,474403 \\
\hline P39 & 4348 & 9909 & 0,438793 \\
\hline P40 & 4029 & 10378 & 0,388225 \\
\hline P41 & 3476 & 11267 & 0,308512 \\
\hline P42 & 4017 & 12063 & 0,333002 \\
\hline P43 & 4791 & 13538 & 0,353893 \\
\hline P44 & 1492 & 13245 & 0,112646 \\
\hline P45 & 819 & 12468 & 0,065688 \\
\hline P46 & 3816 & 11766 & 0,324324 \\
\hline P47 & 4762 & 10391 & 0,458281 \\
\hline P48 & 8479 & 10909 & 0,777248 \\
\hline P49 & 8451 & 10338 & 0,81747 \\
\hline P50 & 9660 & 10159 & 0,950881 \\
\hline P51 & 8630 & 9235 & 0,934488 \\
\hline P52 & 8122 & 9172 & 0,885521 \\
\hline P53 & 6572 & 8490 & 0,774087 \\
\hline P54 & 5720 & 7025 & 0,814235 \\
\hline P55 & 5802 & 6187 & 0,937773 \\
\hline P56 & 2882 & 3844 & 0,74974 \\
\hline P57 & 360 & 1185 & 0,303797 \\
\hline P58 & 372 & 1454 & 0,255846 \\
\hline P59 & 62 & 1068 & 0,058052 \\
\hline & & & \\
\hline & & & \\
\hline
\end{tabular}




$\begin{gathered}\text { XVII Simpósio Brasileiro } \\ \text { de Geografia Fisica Aplicada }\end{gathered}$
$\begin{aligned} & \text { I Congresso Nacional } \\ & \text { de Geografia Física }\end{aligned}$$\quad \begin{gathered}\text { Campinas - SP } \\ 28 \text { de Junho à } 02 \text { de Julho de } 2017\end{gathered}$

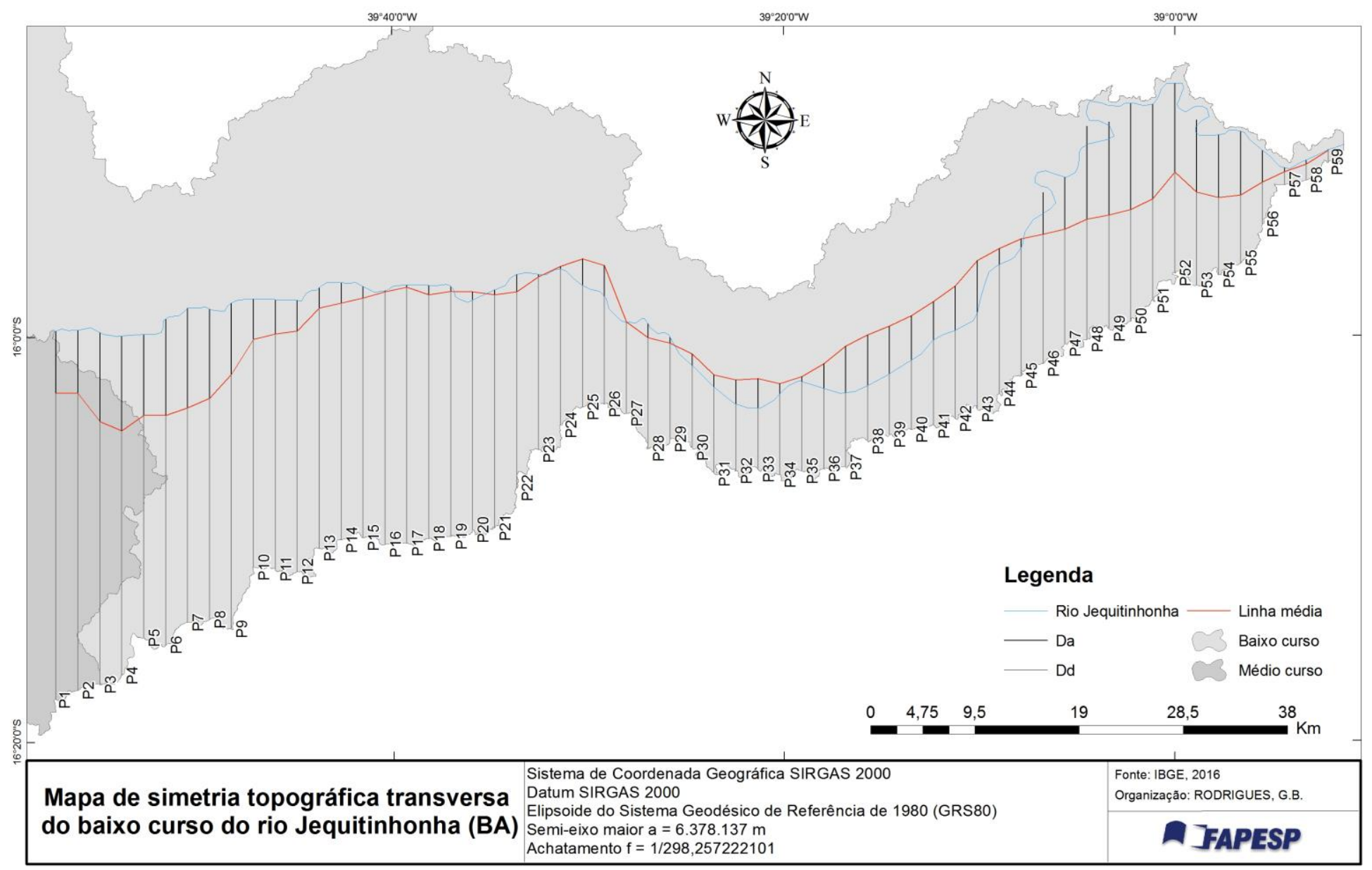

Figura 3 - Fator de Simetria Topográfica Transversa (FSTT)

Os trechos de erosão e deposição sedimentar coincidiram com a mudança de classe de solos mais intemperizados (latossolos, argissolos) na primeira parte e menos intemperizados (chernossolos, gleissolos e neossolos) na segunda parte. Solos menos intemperizados são de formação mais recente e, no caso da área analisada, de formação holocênica (EMBRAPA, 2017). Os dados apresentados coincidem com as estrias encontradas perto do delta do rio Jequitinhonha (BA), explicitadas na figura 3 com imagens da constelação Digital Globe no Google Earth Pro. Essas estrias são evidências de trangressões e regressões marinhas e formam patamares mais recentes que os encontrados a montante.

O FSTT auxiliou na compreensão dos meandros abandonados e dos paleocanais encontrados no baixo curso da bacia hidrográfica, mostrando que o canal fluvial teve o curso muito próximo da linha média do eixo da bacia. Entre os pontos P1 e P15 (Figura 3), o antigo talvegue é mostrado na porção mais ao sul do atual trajeto do rio e, como está exposto na figura 4, coincide com os paleocanais presentes nas imagens 


$\begin{aligned} & \text { XVII Simpósio Brasileiro } \\ & \text { de Geografia Fisica Aplicada }\end{aligned}$
$\begin{aligned} & \text { I Congresso Nacional } \\ & \text { de Geografia Física }\end{aligned}$

orbitais. A figura 4 mostra um paleocanal em destaque, porém foram encontradas evidências de paleocanais que coincidem com a linha média ao longo de todo o baixo curso da bacia do rio Jequitinhonha (BA).

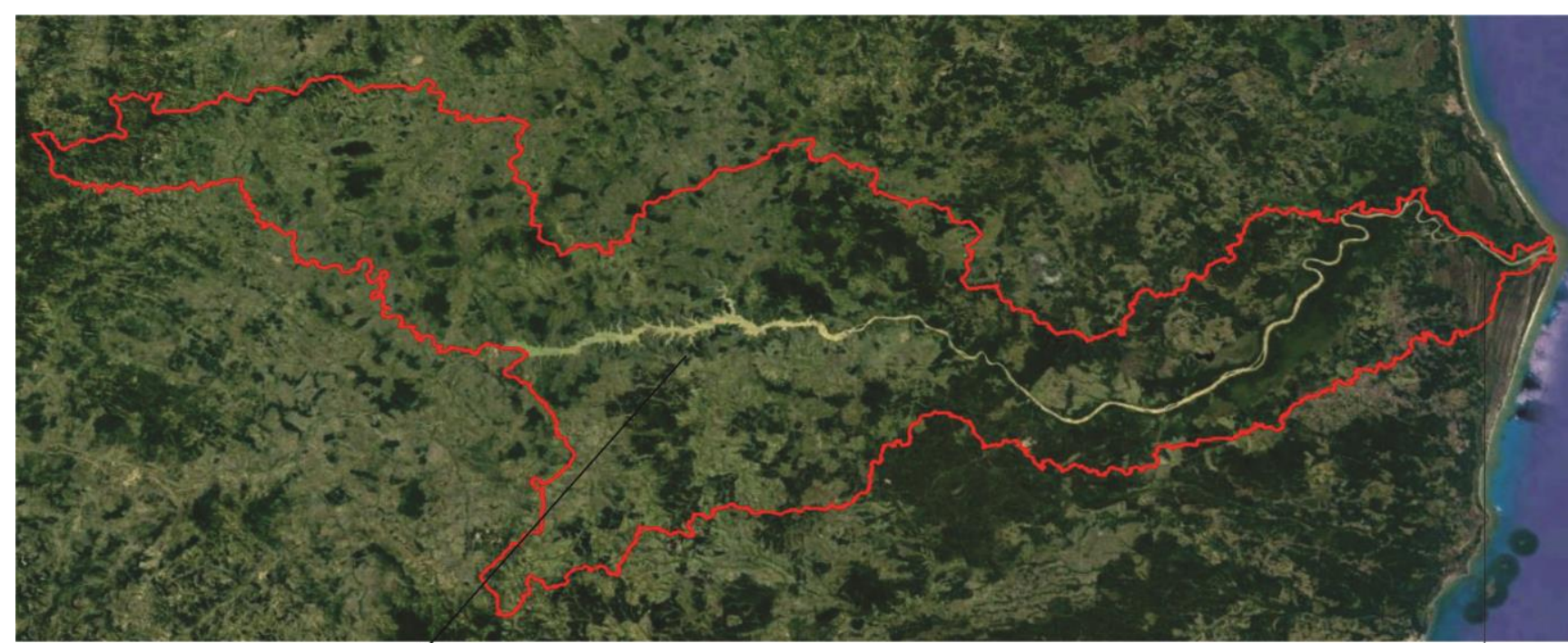

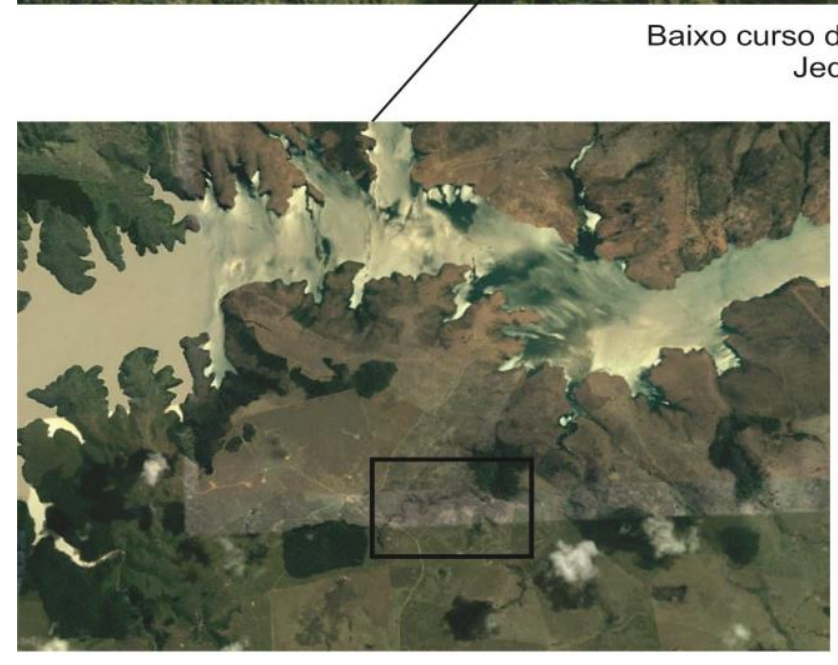

Paleocanal da bacia hidrográfica do rio equitinhonha (BA)

Figura 4 - Paleocanal e estrias marinhas do baixo curso da bacia hidrográfica do rio Jequitinhonha (BA). Fonte: GOOGLE, 2017. Organização: RODRIGUES, G.B.

\section{Considerações finais}

As análises do perfil longitudinal e do FSTT evidenciaram dinâmicas - erosão, deposição sedimentar e comportamento do curso do canal fluvial - que ocorreram e ainda ocorrem no baixo curso do rio 
Jequitinhonha (BA). Os dados pedológicos, geológicos e as estrias marinhas indicam a possibilidade de transgressões e regressões marinhas na área de estudo.

A metodologia se mostrou pertinente, pois permitiu resultados que coincidem com feições presentes em imagens orbitais, e possibilita que novos índices morfométricos sejam agregados à base de dados apresentada neste trabalho.

\section{Agradecimentos}

Agradecemos à Fundação de Amparo e Apoio à Pesquisa do Estado de São Paulo (Fapesp) pelo apoio e pelo financiamento à pesquisa, por meio do projeto número 2016/11006-8.

\section{Bibliografia}

AB 'SÁBER, A.N. Os domínios de natureza no Brasil: potencialidades paisagísticas. São Paulo: Ateliê Editorial, 2003.

CBPM - Companhia Baiana de Recursos Minerais. Projeto Costa do Descobrimento. Salvador: CBPM, 2000.

COX, R.T. Analysis of drainage basin symmetry as a rapid technique to identify areas of possible Quaternary tilt-block tectonics: an example from the Mississippi Embayment. Geol. Soc. Am. Bull, v. 106, 571-581, 1994.

CHRISTOFOLETTI, A. Geomorfologia. São Paulo: Edgard Blücher, 2 ${ }^{\mathrm{a}}$ ed., 1980.

EMBRAPA - Empresa Brasileira de Pesquisa em Agropecuária. Agência Embrapa de Informação Tecnológica. Disponível em: www.agencia.cnptia.embrapa.br. Acessado em: 02/03/2017.

GOOGLE. Google Earth. Versão 7.1.8.3036. Foz do rio Jequitinhonha (BA). Disponível em: https://www.google.com/earth/download/ge/agree.html. Acesso em 02/03/2017.

HACK, J.T. Stream-profile analysis and stream-gradient index. Journal of Research of the United State Geological Survey, v.1, n. 4, p. 421-429, 1973

IBGE - Instituto Brasileiro de Geografia e Estatística. Geociências. Disponível em: http://downloads.ibge.gov.br/downloads geociencias.html. Acesso em: 02/03/2017.

SEI - Superintendência de Estudos Econômicos e Sociais da Bahia. Mapas digitalizados do Estado da Bahia: base de dados. Salvador: SEI, 2004.

TANNER, W.F. The river profiles. Journal of Geology, v. 79, p. 482-492, 1971. 